\title{
Atrioventricular dissociation in acute rheumatic fever
}

\author{
N. Cristal, J. Stern, and M. Gueron \\ From the Department of Medicine ' $B$ ' and the Cardiac Laboratory, \\ The Negev Central Hospital, Beer-Sheva, Israel
}

Enhanced nodal pacemaker activity, manifested in the electrocardiogram as atrioventricular dissociation, appeared in 20 per cent of an unselected group of young adults with acute rheumatic fever.

Though the arrhythmia seemed to reflect myocardial involvement by the rheumatic process, it did not correlate with the clinical diagnosis of 'carditis', and its presence had not the prognostic and therapeutic implications of this condition.

The arrhythmia may be found to be of considerable value in the diagnosis of acute rheumatic fever. However, more material should be collected to substantiate this assumption.

It is well known that rheumatic activity is one of the major causes of atrioventricular dissociation (Pick and Dominguez, I957; Jacobs, Donoso, and Friedberg, 1961; Marriott, Schubart, and Bradley, I958; Schott, I960; Bellet, 1963). However, little attention has been paid to the true incidence and significance of this specific rhythm disturbance in acute rheumatic fever (Gasul, Arcilla, and Lev, 1966; Stein and Bartlett, 1946). Langendorf and Pick (1954) drew attention to the frequent occurrence of the arrhythmia in acute rheumatic fever in children, but few reports have been published on the incidence of atrioventricular dissociation in the young adult (Stein and Bartlett, 1946; Wendkos and Noll, 1944; Zimdahl, 1952). Some investigators have maintained that it is a non-specific and irrelevant feature during the rheumatic process (Stein and Bartlett, 1946; Weller, 1951), while others believe that its appearance is a sign of carditis (Pick and Dominguez, 1957; Sokolow, 1948; Goodman and Pick, 196I).

In view of the theoretical and practical importance of this problem, it was thought that a review of the incidence and significance of atrioventricular dissociation in an unselected group of young adults with acute rheumatic fever would be of interest.

\section{Materials and methods}

The clinical charts of 70 patients with a diagnosis of acute rheumatic fever according to the Jones criteria (American Heart Association, 1955), who Received 24 February 1970. were in hospital in our Medical Department during the period September 1960-September 1966 were reviewed. Electrocardiograms for evaluation were available in all cases.

Atrioventricular dissociation was considered to be present when the atria and the ventricles operated independently for more than 3 beats, and when the ventricular rate was the same or exceeded the atrial rate.

Those patients who had atrioventricular dissociation were selected, and attention was paid to the following details:

Clinical data (a) Patient's age, sex, and whether this was the first attack or a recurrence; (b) the relation of the electrocardiographic changes to the clinical signs of active rheumatic fever with or without carditis (Jones criteria, American Heart Association, 1955); and (c) onset of atrioventricular dissociation before the clinical diagnosis of rheumatic activity.

Electrocardiographic data (a) The day of onset as well as the duration of the arrhythmia; (b) the nodal rate during atrioventricular dissociation; and (c) the atrioventricular conduction time was measured after return to sinus rhythm and the PR index was derived (Mirowski, Rosenstein, and Markowitz, 1964; Mirowski, 196I).

\section{Results}

Clinical data Among the 70 patients, 34 were in hospital with their first attack and 36 for a recurrence (Table I). Atrioventricular dissociation was observed in 14 cases. A remarkable feature was its presence in ro out of 18 male patients during their first attack. Only 4 out of 14 patients showed clinical signs of carditis. The onset of the arrhythmia 
TABLE I Frequency of atrioventricular dissociation in patients with acute rheumatic fever

\begin{tabular}{|c|c|c|c|}
\hline \multicolumn{3}{|l|}{ Admissions } & \multirow{2}{*}{$\begin{array}{l}\text { Atrioventricular } \\
\text { dissociation } \\
\text { Io }\end{array}$} \\
\hline First attack & $34\left\{\begin{array}{l}\text { Male } \\
\text { Female }\end{array}\right.$ & $\begin{array}{l}18 \\
16\end{array}$ & \\
\hline Recurrent attack & $36\left\{\begin{array}{l}\text { Male } \\
\text { Female }\end{array}\right.$ & $\begin{array}{l}25 \\
\text { II }\end{array}$ & $\begin{array}{l}2 \\
\mathbf{I}\end{array}$ \\
\hline Total & 70 & & 14 \\
\hline
\end{tabular}

preceded the full-blown pattern of rheumatic activity in 6 patients (Table 2).

Electrocardiographic data The nodal pacemaker rate ranged between 71 and 125 beats a minute, well within the limits of the definition of active nodal rhythm (Pick and Dominguez, 1957; Marriott and Menendez, 1966). In subsequent electrocardiograms the nodal rate decreased simultaneously with disappearance of the clinical signs of rheumatic activity (Pick and Dominguez, 1957) (Fig. A). The enhanced nodal activity appeared on the first hospital day in II patients and on the second day in the remaining 3 (Fig. B). The arrhythmia was present only during the first day in 4 patients (in some only in a few leads of the available record). In the remaining Io patients it persisted for more than one day (Fig. A, C).

The atrioventricular conduction time was delayed in 7 patients ( $P R$ index greater than

$\forall(I \cdot 00)$. In 2 , it was at the upper limit of normal $(\mathrm{I} \cdot 0)$ and was normal in 4 patients (Fig. D). In one patient the PR was not ameasurable.

\section{Comment}

In the reported studies, the incidence of atrio-

- ventricular dissociation in acute rheumatic fever was low (Stein and Bartlett, 1946; -Wendkos and Noll, 1944; Zimdahl, 1952; Weller, 195I). Our findings show that in an unselected group of young adults with acute -rheumatic fever and specific electrocardiographic criteria, the arrhythmia was present ain 20 per cent of the entire series.

Atrioventricular dissociation was noted only during the first 48 hospital hours, and may be a transient feature. It has been emThasized by Pick and Dominguez (1957) that it may be overlooked due to lack of adequate electrocardiographic control and interpretation. Its onset may be elicited by taking the record during deep inspiration.

- + From the clinical data, the most striking finding was the absence of carditis in ro out of 14 patients. In 6 of our patients, the
TABLE 2 Clinical data of 14 patients showing atrioventricular dissociation

\begin{tabular}{|c|c|c|c|c|c|c|c|c|}
\hline \multirow{2}{*}{$\begin{array}{l}\text { Case } \\
\text { No. }\end{array}$} & \multirow{2}{*}{$\begin{array}{l}\text { Age } \\
(y r .)\end{array}$} & \multirow[t]{2}{*}{ Sex } & \multicolumn{2}{|c|}{ Attack } & \multirow{2}{*}{\multicolumn{2}{|c|}{ Carditis }} & \multirow{2}{*}{\multicolumn{2}{|c|}{$\begin{array}{l}\text { Atrioventricular } \\
\text { dissociation before } \\
\text { clinical diagnosis }\end{array}$}} \\
\hline & & & First & $\begin{array}{l}\text { Recur- } \\
\text { rence }\end{array}$ & & & & \\
\hline I & 16 & $\mathbf{M}$ & I & & No & & No & \\
\hline 2 & 13 & $\mathbf{M}$ & I & & No & & No & \\
\hline 3 & 17 & $\mathbf{M}$ & I & & & Yes & No & \\
\hline 4 & 19 & $\mathbf{M}$ & I & & No & & No & \\
\hline 5 & 19 & $\mathbf{M}$ & & 2 & No & & No & \\
\hline 6 & 15 & M & I & & No & & & Yes \\
\hline 7 & 13 & $\mathbf{M}$ & I & & No & & & Yes \\
\hline 8 & 13 & $F$ & I & & No & & No & \\
\hline 9 & 14 & $\mathbf{M}$ & I & & & Yes & No & \\
\hline I0 & 13 & $\mathbf{F}$ & & 4 & No & & & Yes \\
\hline II & 13 & $\mathbf{M}$ & & 2 & & Yes & & Yes \\
\hline 12 & 13 & $\mathbf{M}$ & I & & No & & & Yes \\
\hline I3 & 13 & $\mathbf{M}$ & I & & & Yes & No & \\
\hline 14 & 17 & $\mathbf{M}$ & $\mathbf{I}$ & & No & & & Yes \\
\hline Total & & & II & 3 & I0 & 4 & 8 & 6 \\
\hline
\end{tabular}

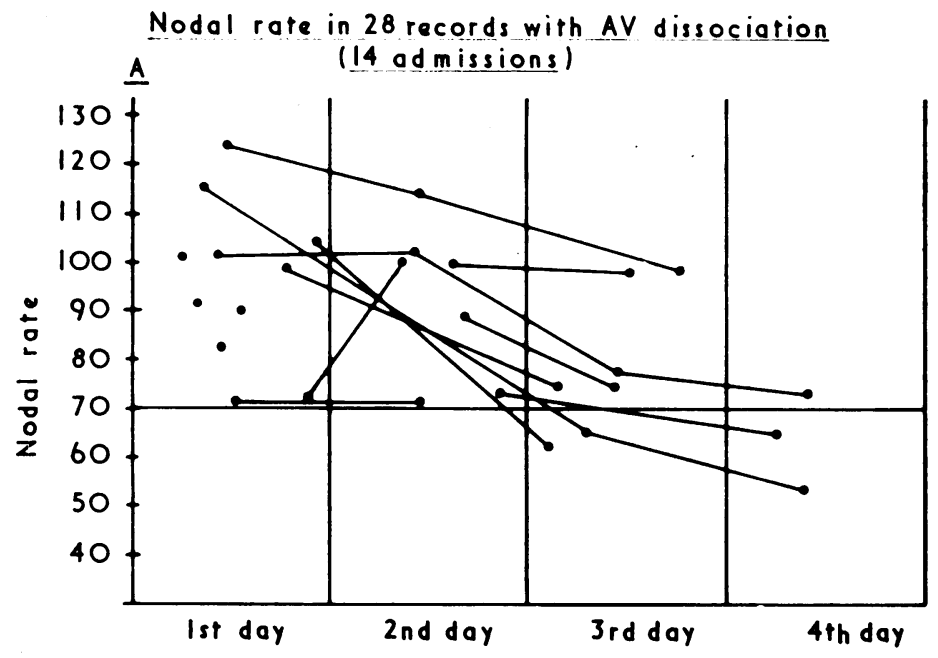

B Day of onset

C Duration

D PR index
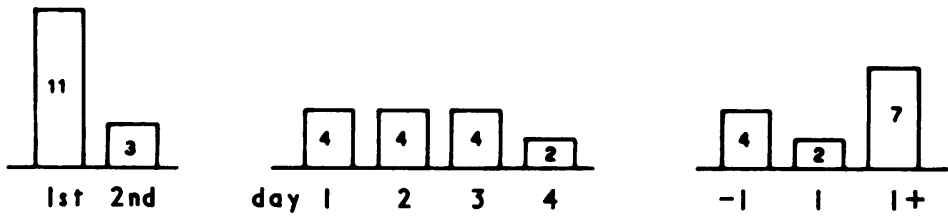

FIG. I Electrocardiographic data. 
arrhythmia was present before the diagnosis of rheumatic activity was established.

Our study indicates that when atrioventricular dissociation is present in acute rheumatic fever it is always the consequence of enhanced nodal pacemaker activity, with or without some delay in the atrioventricular conduction. Therefore, the presence of this increased nodal impulse generation ('by usurpation' mechanism) (Marriott et al., 1958; Schott, 1960; Marriott and Menendez, 1966; Bellet, 1963) - 'acceleration of a subsidiary pacemaker' (Pick, I963), reflects a pathological state within the heart (Pick and Dominguez, 1957; Marriott et al., 1958; Marriott and Menendez, 1966; Bellet, 1963; Grant, 1956).

These observations point to the absence of correlation between carditis as diagnosed electrocardiographically, and carditis diagnosed on purely clinical grounds.

To overcome, in part, the above-mentioned lack of correlation that results from an indiscriminate use of the term 'carditis', we suggest the existence of two different conditions, namely 'myocardial damage' and 'myocardial involvement'. In the former, the rheumatic process causes widespread and generally irreversible structural changes in the heart. These changes manifest themselves as cardiac enlargement, congestive heart failure, changing murmurs, or pericarditis. In 'myocardial involvement' these changes are of a much lesser grade, so that it may not be possible to detect them by clinical methods. Here the rheumatic process injures specially vulnerable structures. The injury seems to be more localized and probably transient. The exact nature of this involvement is not clearly defined at present. Toxic or inflammatory reactions have been blamed (Stein and Bartlett, 1946; Langendorf and Pick, 1954; Wendkos and Noll, 1944; Zimdahl, 1952; Weller, 1951 ; Sokolow, 1948; Goodman and Pick, 196I; American Heart Association, 1955; Mirowski et al., 1964; Mirowski, 1961 ; Marriott and Menendez, 1966; Pick, 1963; Grant, 1956; Gross and Fried, 1936), as well as neurohumoral factors (Mirowski et al., 1964; Mirowski, I96I; Marriott and Menendez, 1966; Pick, 1963; Grant, 1956; Gross and Fried, 1936; Bruenn, 1937). Apposition of antibodies in the cell membrane of specific cardiac structures has been suggested, and its presence was shown in some cases (Kaplan et al., 1964).

Our impression is that the electrocardiogram may offer us a sensitive enough means to detect such subtle changes (Sokolow, 1948; Grant, 1956; Blackman and Hamilton, 1948).
Though the exact mechanism of the enhanced nodal activity in acute rheumatic fever is not defined by the present study, our data suggest that this disturbance may be of value as an aid to the diagnosis of this disease. However, its presence bears no relation to the diagnosis of carditis and to the prognosis of the patient.

\section{References}

American Heart Association (1955). Jones criteria (modified) for guidance in the diagnosis of rheumatic fever. New York.

Bellet, S. (1963). Clinical Disorders of the Heart Beat, and ed., p. 424. Lea and Febiger, Philadelphia.

Blackman, N. S., and Hamilton, C. I. (1948). Serial electrocardiographic changes in young adults with acute rheumatic fever; report of 62 cases. Annals of Internal Medicine, 29, 416.

Bruenn, H. G. (1937). The mechanism of impaired auriculo-ventricular conduction in acute rheumatic fever. American Heart fournal, 13, 413.

Gasul, B. M., Arcilla, R. A., and Lev, M. (1966). Heart Disease in Children, p. 1203. J. B. Lippincott, Philadelphia.

Goodman, R. M., and Pick, A. (196I). An unusual type of intermittent $A-V$ dissociation in acute rheumatic myocarditis. American Heart fournal, 6r, 259.

Grant, R. P. (1956). The mechanism of A-V arrhythmias with an electronic analogue of the human $A-V$ node. American fournal of Medicine, 20, 334.

Gross, L., and Fried, B. M. (1936). Lesions in the auriculoventricular conduction system occurring in rheumatic fever. American fournal of Pathology, 12, 31 .

Jacobs, D. R., Donoso, E., and Friedberg, C. K. (I96r). A-V dissociation - a relatively frequent arrhythmia. Medicine, 40, ror.

Kaplan, M. H., Bolande, R., Rakita, L., and Blair, J. (1964). Presence of bound immunoglobulins and complement in the myocardium in acute rheumatic fever. Association with cardiac failure. New England Fournal of Medicine, 271, 637.

Langendorf, R., and Pick, A. (1954). Cardiac arrhythmias in infants and children. Pediatric Clinics of North America, 1, 215.

Marriott, H. J. L., and Menendez, M. M. (1966). A-V dissociation revisited. Progress in Cardiovascular Disease, 8, 522.

- Schubart, A. F., and Bradley, S. M. (1958). A-V dissociation: a reappraisal. American fournal of Cardiology, 2, 586.

Mirowski, M. (196I). Diagnostico cualitativo y cuantitativo del bloqueo auriculoventricular de primer grado. Archivos del Instituto de Cardiologia de México, 31, 67.

-, Rosenstein, B. J., and Markowitz, M. (1964). A comparison of atrio-ventricular conduction in normal children and in patients with rheumatic fever, glomerulonephritis, and acute febrile illnesses. Pediatrics, 33, 334.

Pick, A. (1963). A-V dissociation. A proposal for a comprehensive classification and consistent terminology. American Heart fournal, 66, 147.

- , and Dominguez, P. (1957). Nonparoxysmal A-V nodal tachycardia. Circulation, 16, 1022.

Schott, A. (1960). Atrioventricular dissociation with and without interference. Progress in Cardiovascular Disease, 2, 444. 
Sokolow, M. (1948). Significance of electrocardiographic changes in rheumatic fever. American fournal of Medicine, 5, 365.

Stein, I., and Bartlett, A. G. (1946). Interference dissociation - an early finding in acute rheumatic fever. American fournal of the Medical Sciences, 211, 686.
Weller, S. D. V. (195I). Complete A-V dissociation in acute rheumatism. British Heart fournal, 13, 102.

Wendkos, M. H., and Noll, J., Jr. (I944). A survey of rheumatic fever in a large station hospital. Medical Clinics of North America, 28, 124.

Zimdahl, W. T. (1952). Rheumatic fever in young adults. British Heart fournal, I4, 70. 